\title{
因HAD
}

ISSN-L: 2530-5115

DOI: http://doi.org/10.22585/hospdomic.v4i2.101

\section{Efectos del Sevoflurano tópico en úlceras vasculares. A propósito de un caso}

\author{
Efects of topical Sevoflurane in the treatment of vascular \\ ulcers. Report of a clinical case
}

Gema Amparo Navarro-Buendía', Marina Satorres-Pérez', Laura Jiménez-Ruiz', Montserrat Alberdi Bellón'

1. Hospital Universitario de San Juan, Unidad de Hospitalización a Domicilio, Sant Joan d'Alacant, España

Correspondencia/Correspondence

Gema Amparo Navarro-Buendía

gema.navarro2@gmail.com

Recibido/Received

23.02.2020

Aceptado/Accepted

23.03.2020
Conflicto de Intereses/Competing interest

Las autoras del trabajo declaran no tener ningún conflicto de interés.

Financiación

No se han recibido fuentes de financiación.

Agradecimientos/Acknowledgement

A la paciente, por acceder a difundir su caso;

al servicio de Hospitalización a Domicilio del

Hospital San Juan de Alicante, por su actitud

docente. 


\section{RESUMEN}

El sevoflurano es un líquido volátil no inflamable, derivado halogenado del éter que se utiliza para inducción y mantenimiento de la anestesia general, por vía inhalatoria. Se han descrito sus propiedades analgésicas, antimicrobianas y vasodilatadoras en el tratamiento de las úlceras venosas crónicas. En el presente artículo reportamos un caso clínico de utilización de sevoflurano tópico en nuestra unidad, en una paciente que presentaba úlceras venosas sin mejoría tras cuidados estándar. Se inician instilaciones del fármaco, registrando una mejoría del dolor basal y del estado de las úlceras.

Palabras clave: Sevoflurano; Úlcera Cutánea; Cuidados Paliativos.

\section{ABSTRACT}

Sevoflurane is a volatile non-flammable liquid, halogenated derivative of ether and used inhaled for induction and maintenance of general anesthesia. Its analgesic, antimicrobial and vasodilator properties have been described in the treatment of chronic venous ulcers. In this article we report a clinical case of the use of topical sevoflurane in our unit, in a patient who presented with venous ulcers without improvement after standard care. Drug instillations were initiated, recording an improvement in basal pain and the state of ulcers.

Keywords: Sevoflurane; Skin Ulcer; Palliative Care. 


\section{INTRODUCCIÓN}

El tratamiento de las úlceras venosas crónicas (UVC) exige un abordaje integral y complejo, dada la extensa variedad de factores que se asocian a la cicatrización, el dolor asociado a la cura; así como la diversidad de fármacos disponibles. Las medidas estándar que abarcan limpieza, desbridamiento y colocación de apósitos obtienen tasas de curación del 65 al 85\%. No obstante, un 25\% cronifican, menoscabando la salud del paciente y conllevando una disminución de su calidad de vida y autonomía e incremento en morbilidad y coste-efectividad del proceso.

El manejo del dolor es fundamental, un derecho del paciente e indicador de calidad asistencial. Los fármacos sistémicos para control del dolor producido por las úlceras incluyen: el paracetamol en casos leves; los antiinflamatorios y en dolor intenso, los opiáceos. Sin embargo, los efectos adversos en tratamientos crónicos limitan su uso. Los antiinflamatorios no esteroideos pueden producir toxicidad gastrointestinal y cardiovascular y los opioides estreñimiento o depresión respiratoria y neurológica, sobretodo en ancianos. Los tratamientos tópicos aprobados para el dolor de las UVC se basan en cremas de lidocaína y prilocaína $(1,2)$.

El sevoflurano es un líquido volátil no inflamable, derivado halogenado del éter que se utiliza para inducción y mantenimiento de la anestesia general, por vía inhalatoria. Se conserva en envases ámbar de naftalato de polietileno de $250 \mathrm{ml}$, a temperatura ambiente entre 15 y $30^{\circ} \mathrm{C}(3,4)$.

Se ha descrito su uso tópico en irrigación para tratamiento de úlceras cutáneas, con efecto analgésico rápido (3,5-7). En un estudio observacional prospectivo en pacientes con úlceras vasculares crónicas, los pacientes se asignaron a recibir sevoflurano tópico añadido a curas versus sólo cuidados estándar. Se objetivó una disminución del dolor en la Escala Visual Analógica, en el requerimiento de opioides sistémicos y una regresión en el tamaño de la úlcera de forma estadísticamente significativa en el grupo tratado con sevoflurano (8).

Además, en su forma líquida los halogenados tienen capacidad bactericida 5. Se ha sugerido que su aplicación directa posee un efecto antimicrobiano, bactericida in vitro frente a Staphylococcus aureus, Pseudomona aeruginosa y Escherichia coli $(2,7,9)$.

Asimismo, se ha descrito la acción inhibitoria directa del sevoflurano sobre músculo liso vascular, lo que podría suponer un efecto vasodilatador beneficioso para el tratamiento de heridas(5).

Por otro lado, la irrigación de sevoflurano tópico en heridas se ha mostrado una alternativa muy segura, sin reportarse efectos sistémicos (9). Como efectos indeseables únicamente se han documentado el prurito y la irritación perilesional $(1,9)$. Además, no se ha descrito que produzca tolerancia ni sensibilización (2,9).

Por último, destacar que el uso de sevoflurano en este tipo de úlceras que requieren curas de larga evolución, con ingresos hospitalarios y tandas repetidas de antibióticos intravenosos, resulta rentable, como describen Ferrara et al (10).

A continuación, se expone un tratamiento tópico con instilaciones de sevoflurano en nuestra unidad, en una paciente con enfermedad venosa crónica.

\section{DESARROLLO DE LA EXPERIENCIA}

Paciente mujer de 86 años, valorada por la unidad a hospitalización a domicilio en noviembre de 2019, por úlceras venosas en ambos miembros inferiores sin mejoría evolutiva a pesar de curas por enfermería en atención primaria. 
La paciente ingresó en 2013 y 2015 por sobreinfección de las úlceras por Staphylococcus aureus meticilin resistente; en junio de 2019 por Pseudomona aeruginosa. Como antecedentes médicos destacaba: diabetes mellitus, hipertensión, insuficiencia renal crónica estadío 3 secundaria a nefroangioesclerosis/diabetes, ángor hemodinámica, fibrilación auricular revertida, gastritis y esofagitis con pseudoclusión intestinal. Intervenida de prótesis de rodilla izquierda y faquectomía bilateral.

En la primera valoración domiciliaria de la paciente, mostraba úlceras venosas extensas, en ambos miembros inferiores, con exudado amarillo-verdoso (ver Figura 1). Se realizó limpieza, colocación de apósito de plata y vendaje oclusivo. Se recogieron cultivos, en los que creció Pseudomona aeruginosa sensible a ceftazidima, por lo que se pautó vía intravenosa en domicilio, ajustada a su función renal, durante 14 días.

Además, presentaba dolor intenso basal con componente somático y neuropático, a pesar de tratamiento sistémico con paracetamol más tramadol, con una puntuación de dolor basal mediante Escala Visual Analógica de 9.

Dado el dolor no controlado y el componente infeccioso, se propuso el uso de sevoflurano tópico sobre las lesiones a farmacia hospitalaria, fuera de ficha técnica y previo consentimiento informado de la paciente. El producto se conservó en un frasco de $250 \mathrm{ml}$ de sevoflurano al 100\%, con llave de tres pasos para cerrar el acceso y facilitar la extracción (ver Figura 1). Se transportó al domicilio en jeringas de $10 \mathrm{ml}$, protegido de luz y calor. Durante 2 meses se limpió la úlcera con suero fisiológico y gasas estériles y posteriormente fue tratada con instilaciones tópicas de sevoflurano evitando que el anestésico contactara con la piel sana periulcerosa. Se colocó apósito de plata posterior.

Transcurrido este tiempo, las lesiones tuvieron una evolución favorable (ver Figura 1) y el dolor en la Escala Visual Analógica disminuyó a 6. No se reportaron efectos adversos.

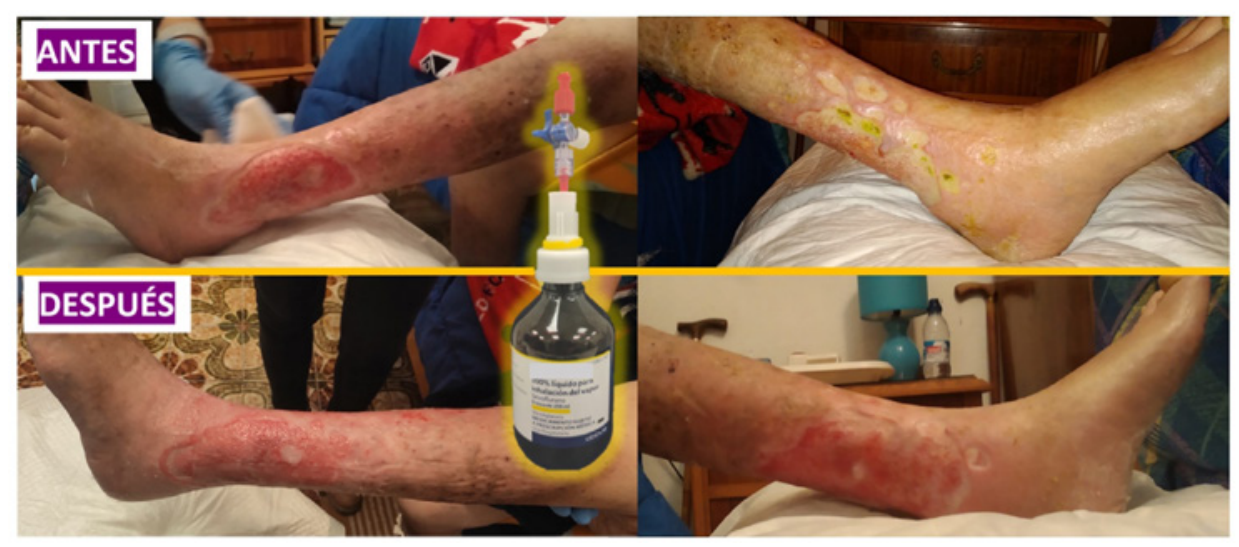

Figura 1: Evolución úlceras vasculares tras tratamiento tópico con sevoflurano. 


\section{CONCLUSIONES}

El manejo de las úlceras venosas crónicas es complejo, precisando de tratamientos combinados sistémicos y tópicos y siendo el dolor el principal síntoma asociado.

El sevoflurano es un anestésico inhalatorio de uso hospitalario que recientemente se ha empezado a utilizar de forma tópica para curas de úlceras tórpidas crónicas de diversa índole (neoplásicas, vasculares, diabéticas o por presión).

Este fármaco posee propiedades analgésicas, antimicrobianas y vasodilatadoras que favorecen la cicatrización de la herida con buena evolución y rapidez, así como escasos efectos adversos.

En nuestro caso clínico reportamos la mejora significativa en la evolución de úlceras vasculares de evolución tórpida con gran afectación sobre la calidad de vida de la paciente, que con las técnicas habituales precisó analgesia con derivados opioides.

\section{BIBLIOGRAFÍA}

1. Imbernón-Moya A, Ortiz-de Frutos FJ, Sanjuan-Álvarez M, Portero-Sánchez I, Aguilar-Martínez A, Gallego-Valdés MA. Tratamiento del dolor en úlceras venosas crónicas. Piel (Barc). 2017;32(9):556-8. DOI: 10.1016/j.piel.2017.03.004

2. Centro Tecnológico de Información y Documentación Sanitarias. Uso tópico, del sevoflurano en heridas crónicas [monografía en Internet]. Murcia, España: Banco de Preguntas, Preevid Murciasalud, Consejería de Salud de la Región de Murcia; 2018 [consultada 14 mar 2020]. Disponible en http://www.murciasalud.es/preevid/22279

3. Fernández-Ginés FD, Cortiñas Sáenz M, Férnandez Sánchez C, Morales-Molina JA. Sevoflurano tópico: una nueva opción terapéutica paliativa en las úlceras cutáneas. Med Paliat. 2015;24(2):108. DOI: 10.1016/j.medipa.2015.03.003

4. Agencia Española de Medicamentos y Productos Sanitarios. Ficha técnica de medicamento (Sevorane®) [mongrafía en Internet]. Madrid, España: Ministerio de sanodad; 2018 [consultada 3 feb 2020]. Disponible en: https://cima.aemps.es/cima/pdfs/es/tt/61451/61451_ft.pdf

5. Imbernón-Moya A, Sanjuan-Álvarez M, Ortiz-de Frutos FJ, Portero-Sánchez I, Aguilar-Martínez A, Gallego-Valdés MA. Sevoflurano. Efectos vasodilatador, analgésico, bactericida y cicatrizante. Piel (Barc). 2018;33(3):180-3. doi: 10.1016/j.piel.2017.05.031.

6. Amores Valenciano P, Navarro Carrillo Alicia, Romero Cebrián MA, Gerónimo-Pardo M. Sevoflurano tópico como terapia de rescate de dolor refractario en úlceras venosas crónicas. Emergencias 2018;30(2):138.

7. Fernández-Ginés FD, Cortiñas-Sáenz M, Agudo-Ponce D, Navajas-Gómez de Aranda A, Morales-Molina JA, Fernández-Sánchez $C$, et al. Pain reduction of topical sevoflurane vs intravenous opioids in pressure ulcers. Int Wound J. 2020;(1):83-90. DOI: 10.1111/iwj.13235; PMID: 31762163

8. Fernández-Ginés FD, Cortiñas-Saenz M, Mateo-Carrasco H, Navajas-Gómez de Aranda A, Navarro-Muñoz E, Rodríguez-Carmona R, et al. Efficacy and safety of topical sevoflurane in the treatment of chronic skin ulcers. Am J Health-Syst Pharm. 2017;74(9):e176-82. DOI: 10.2146/ ajhp151008; PMID: 28438822 
Notas clínicas: Navarro-Buendía GA, Satorres-Pérez M, Jiménez-Ruiz L, Alberdi Bellón M.

9. Gerónimo Pardo M, Cortiñas Sáenz M. Eficacia analgésica del sevoflurano tópico en heridas. Rev Soc Esp Dolor 2018;25(2):106-11. DOI: 10.20986/resed.2017.3617/2017

10. Ferrara P, Domingo-Chiva E, Selva-Sevilla C, Campos-García J, Gerónimo-Pardo M. Irrigation with Liquid Sevoflurane and Healing of a Postoperative, Recurrent Epidural Infection: A Potential Cost-Saving Alternative. World Neurosurgery. 2016;90:702.e1-702.e5. DOI: 10.1016/j. wneu.2016.02.079; PMID: 26924116 